\title{
EDUCAÇÃO AMBIENTAL
}

\section{ANÁLISE DA INSERÇÃO DA EDUCAÇÃO AMBIENTAL NAS ESCOLAS PÚBLICAS DOS MUNÍCIPIOS DE ALVORADA DO OESTE E POMENTA BUENO- RO.}

\author{
Lila Francisca de. O. R. Matos - lila@ unescnet.br \\ UNESC - Faculdades Integradas de Cacoal - RO. \\ Camila Pereira de Andrade - millaandrade93@ hotmail.com \\ UNESC - Faculdades Integradas de Cacoal - RO. \\ Caroline Silvério Maran - carolinemaran@ hotmail.com \\ UNESC - Faculdades Integradas de Cacoal - RO.
}

RESUMO: Este artigo tem como objetivo comparar, a inserção da Educação Ambiental nas matrizes curriculares nas escolas públicas municipais e estaduais dos municípios de Alvorada do Oeste e Pimenta Bueno - RO. Os dados foram obtidos por entrevistas destinadas aos gestores das escolas participantes, compreendendo como a EA vem sendo trabalhada nas escolas das quais fazem parte. Conclui-se que, na maioria das escolas se trabalha o tema de forma pontual, isto é, com projetos e atividades esporádicas durante o ano letivo, tendo em vista necessidade de mais importância sobre a conscientização dos alunos com a sustentabilidade.

Palavras Chave: Diretrizes curriculares, Interdisciplinaridade, Meio ambiente, Tema Transversal.

\section{INTRODUÇÃO}

Com a Constituição Federal Brasileira (1988), foi destacada a responsabilidade do Poder Público na inserção da Educação Ambiental nas escolas e conscientização da população para a preservação do meio ambiente, porém, somente com a criação da Política Nacional de Educação Ambiental (Lei no . 9.795/99), foi possível a implementação da EA no âmbito do Ensino Fundamental no Brasil (MOLINA et al., 2012). Aliado a isto, foram criados os Parâmetros Curriculares Nacionais - PCN's, não como lei, mas como a introdução do tema EA de forma interdisciplinar, incorporado em todos os níveis de ensino fundamental, que define em seus princípios a concepção de ambiente em sua totalidade e a garantia de continuidade e permanência do processo educativo, destacando-se seu enfoque democrático e participativo (RODRIGUES, 2011; OLIVEIRA; LEMOS, 2011). 

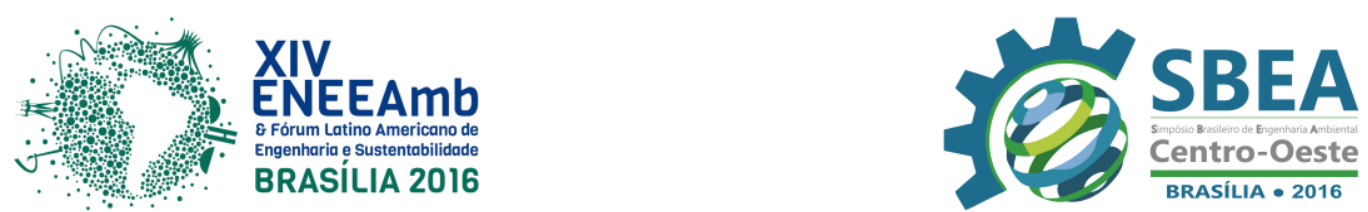

Nesse sentido, a Educação Ambiental deve cumprir o papel no ensino e aprendizagem educacional de promover a solução dos problemas ambientais e uma melhor qualidade de vida para todos (REIGOTA, 2002). As atividades escolares poderão servir como instrumento de mudança de comportamento com relação ao Meio Ambiente, no sentido de aquisição de valores éticos sociais e atitudes comprometidas com a preservação ambiental, uma vez que as crianças passam grande parte do tempo de sua formação enquanto indivíduo na escola (JACOBI, 2003; TRISTÃO, 2005).

A inserção da Educação Ambiental nos currículos escolares deve se dar de forma holística, ou seja, de forma a visualizar a questão como um todo (TRISTÃO, 2005), e deve ser repassada como um tema transversal, de forma a atuar em uma dimensão que permeie todas as atividades escolares (ZAKRZEVSKI; SATO, 2007).

Apesar de toda a discussão acerca da importância de incorporar a Educação Ambiental como temática transversal, de forma holística, democrática e integradora, nem sempre as escolas têm atuado nesse sentido. Diante do exposto, o presente trabalho tem como objetivo comparar a inserção da educação ambiental nas escolas públicas municipais e estaduais dos municípios de Alvorada do Oeste e Pimenta Bueno - RO.

\section{MÉTODO}

Inicialmente foi realizada uma pesquisa bibliográfica sobre a Educação Ambiental, a fim de proporcionar embasamento sobre o tema. Em seguida, foi elaborado um roteiro de entrevista semiestruturada a fim de investigar junto aos gestores de escolas públicas dos municípios de Alvorada do Oeste e de Pimenta Bueno - RO, como a educação ambiental é inserida nas escolas.

O questionário foi respondido por diretores de dezessete escolas de ensino fundamental, sendo onze escolas públicas estaduais e seis escolas públicas municipais. A opção pelas escolas de ensino fundamental se deu com base na determinação contida nos Parâmetros Curriculares Nacionais (PCNs), previstos pelo Ministério da Educação. Nele estabelece-se que no ensino fundamental, a escola deve oferecer meios para que o aluno entenda a realidade ambiental, de forma que, ao terminar esta etapa, já consciente desta questão, os alunos possam colaborar para a construção de uma sociedade sustentável (MOLINA et al,; 2012; SANTOS; MORAES, 2009). 


\section{RESULTADOS E DISCUSSÃO}

A análise dos dados coletados por meio de entrevista aos diretores de escola revela que, dentre as escolas municipais, apenas uma desenvolve um projeto que trabalha a temática da educação ambiental de forma holística, ou seja, transversal às disciplinas que compõem a grade curricular e ao longo de todo o período letivo, figura 1. As outras duas escolas apresentam projetos de educação ambiental, entretanto os mesmo são desenvolvidos de forma pontual, ou seja, em determinada época do ano. Interessante salientar ainda que, nestas escolas, o projeto é desenvolvido na mesma época devido a uma iniciativa de apresentação das atividades relacionadas ao tema que envolve todas as escolas da cidade. Desse modo, três escolas não desenvolve nenhum tipo de projeto. Isso demonstra que a educação ambiental, não só está sendo trabalhada em uma época específica do ano, como ainda, está destinada à demanda externa de atividades relacionadas ao meio ambiente, e não como parte da realidade da criança nas atividades escolares diárias.

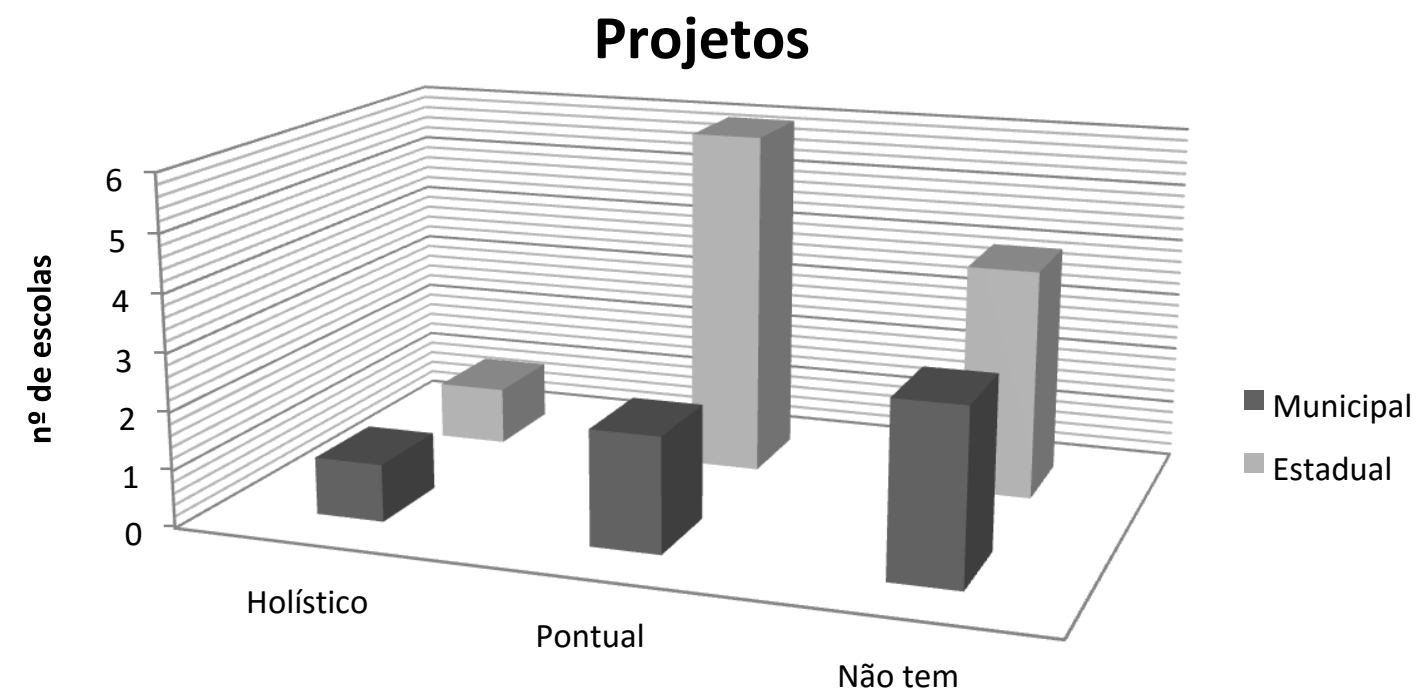

Gráfico 01: Escolas que apresentam projetos de forma holística ou pontual da EA.

Nas escolas estaduais a situação é ainda mais complicada, pois, das onze instituições investigadas, uma desenvolve projeto de forma holística, seis realizam projetos de educação ambiental de forma pontual, e quatro não apresenta nenhuma atividade relacionada ao tema. Foi possível observar também que, as das seis escolas que apresentam projetos pontuais de educação ambiental estão relacionados às datas relacionadas ao meio ambiente e uma delas ou à inserção da escola em gincanas ou eventos promovidos por órgãos externos. 

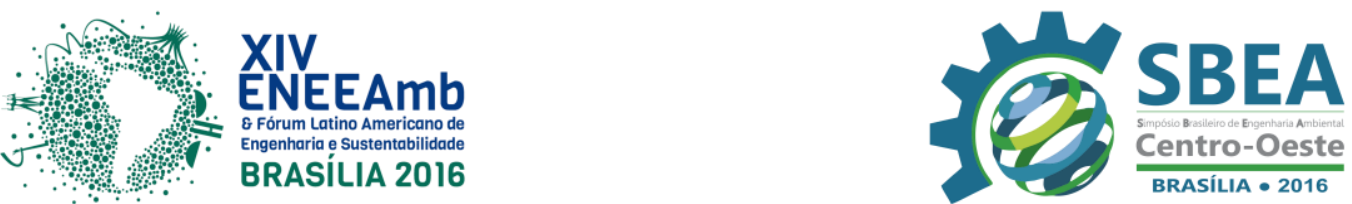

\section{Como é trasmitido?}

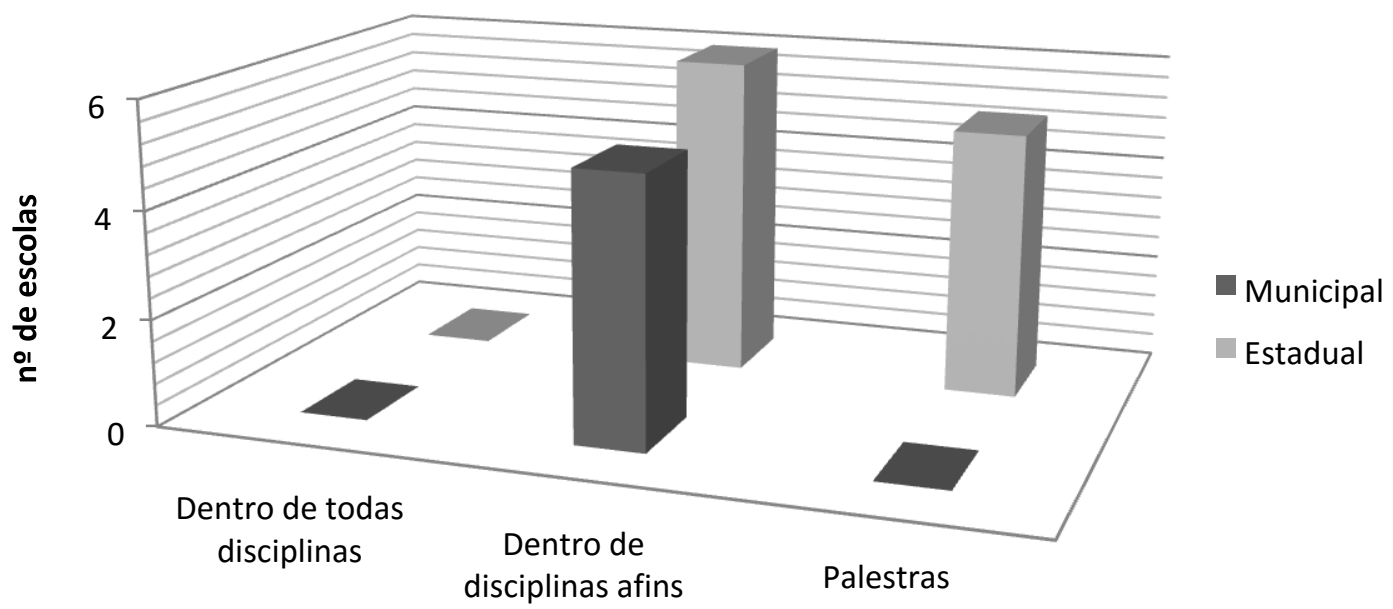

Gráfico 02: Como é transmitida a temática da educação Ambiental

Com relação à forma como a educação ambiental é transmitida aos alunos, figura 2, observou-se que na maioria das escolas municipais a temática é trabalhada nas disciplinas afins, ou seja, não de forma isolada ou independente, mas de forma e integrar e perpassar o tema em diversas áreas do saber. Isso possibilita que a relação homem e meio ambiente seja discutida sob mais de uma perspectiva em sala de aula e o aluno possa internalizar valores a serem convertidos em atitudes relacionadas à preservação.

Nas escolas estaduais, a temática da educação ambiental é trabalhada, na maioria dos casos, na forma de disciplinas afins da grade curricular. Podendo notar-se que em cinco escolas o tema esta sendo transmitido através de palestras ministradas por profissionais da área ambiental aos alunos em momentos específicos da trajetória escolar ao longo do ano letivo. Dessa forma, não há o desenvolvimento de uma relação de proximidade com o tema, uma vez que esse contato ocorre em ocasiões específicas como "Dia da Água", por exemplo. 


\section{Recebe apoio financeiro para o EA?}

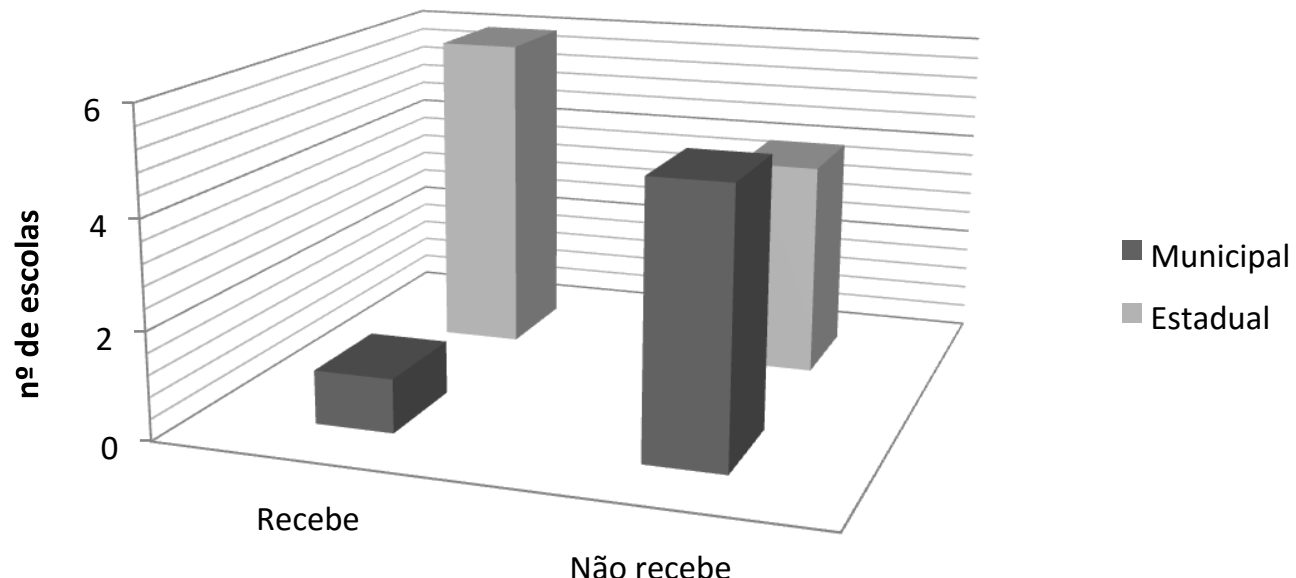

Gráfico 03 : Escolas que recebem ou não o apoio financeiro para fins de EA.

Com relação ao apoio financeiro do governo municipal, estadual ou federal para a realização dos projetos relacionados à Educação Ambiental nas escolas, gráfico 3, observa-se que nas escolas municipais apenas uma recebe apoio e quatro não recebem recursos financeiros, sendo que nas escolas estaduais cinco recebe apoio e a seis não recebem apoio algum. Isso reflete a dificuldade na inserção da temática em práticas educativas mais elaboradas, uma vez que embora previsto pela Política Nacional de Ambiental, e diante da importância do tema para uma mudança de comportamento e adoção de valores e práticas relacionados à preservação dos recursos, não há investimento em educação ambiental rumo a uma sociedade mais sustentável.

\section{Gestão de impactos?}

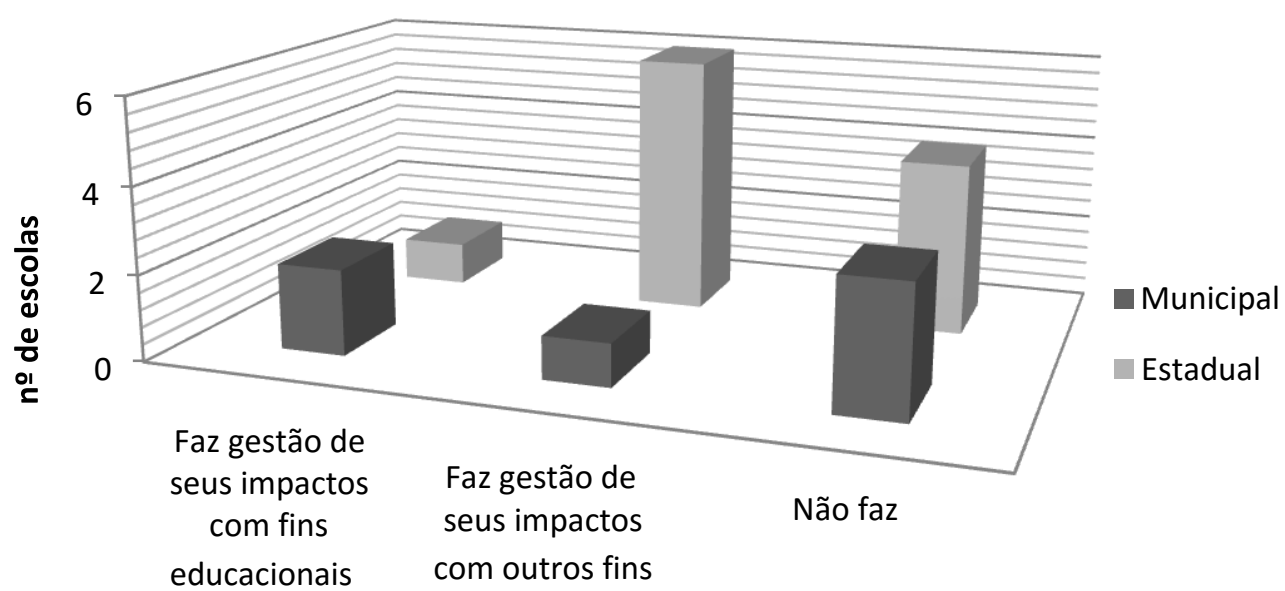

Gráfico 04: Escolas que acontecem gestão de impactos sobre o EA. 

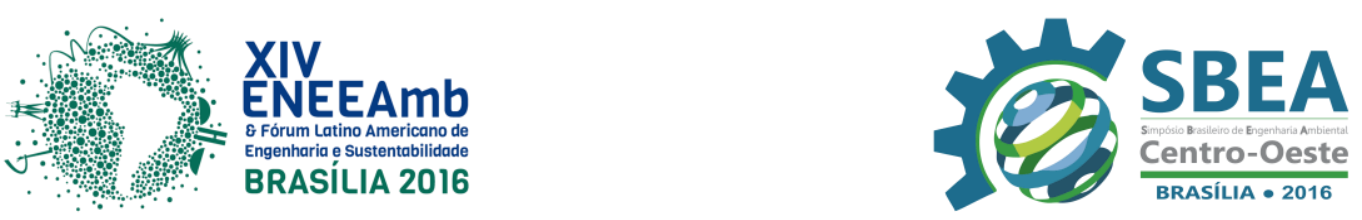

Em relação à gestão dos impactos da própria instituição de ensino, duas das escolas municipais faz gestão com fins educacionais, uma faz gestão com outros fins, sendo que três não fazem gestão alguma. Das escolas estaduais apenas uma faz gestão com fins educacionais e seis fazem com outros fins e quatro não realizam ações para gestão de seus impactos. Assim, observa-se a falta de responsabilidade sobre o intuito da EA, sendo que a escola deve exercer o papel de principal ferramenta em que aconteça a implementação de valores para a preservação e sustentabilidade do planeta.

\section{CONCLUSÃO}

Levando em conta o que estabelece o art. 225 da Constituição em sua seção VI, é necessário que o Poder Público coloque em prática a questão de promover a Educação Ambiental nas instituições de ensino, criando uma relação mais estreita entre o tema e a realidade, inserindo em sua matriz curricular deixando visível a verdadeira necessidade de preservação do meio ambiente, começando a conscientização desde cedo às pessoas, com a execução de projetos e atividades com mais frequência no cotidiano escolar, sendo eles de modo transversal, com o intuito de atingir a diversidade de aspectos ambientais, podendo desenvolver no aluno a plena consciência sobre a preservação ambiental.

O objetivo e expectativas que foram criadas sobre a pesquisa, atenderam as necessidades de conhecimento que se buscou, fortalecendo as habilidades quanto pesquisador e propiciando um saber mais apurado sobre a responsabilidade das entidades escolares a respeito da inserção do tema EA, nos seus currículos de forma ativa e sistemática.

É bom lembrar que não só a escola, como também toda a sociedade e seguimentos produtivos devem colaborar com essa tarefa, pois a verdadeira preservação depende de um conjunto de ações que move o indivíduo. Portanto, se não haver um senso comum de conscientização se tornará difícil estabelecer uma contribuição com atos responsáveis que favoreça a preservação e manutenção do Planeta. 


\section{Referências Bibliográficas}

JACOBI, P. Educação ambiental, cidadania e sustentabilidade. Cadernos de Pesquisa, n. 118, p.189-205, 2003.

MOLINA et al. Avaliação da percepção ambiental em relação a projetos formais de educação ambiental. Educação Ambiental em Ação, n. 41, ano XI, Set.-Nov.,2012.

OLIVEIRA, T. P.; LEMOS, R. M. Promovendo a Educação Ambiental como Instrumento de Aprendizagem nas Escolas do Município de Iguaí, Bahia. Revista Eletrônica do Mestrado em Educação Ambiental. Rio Grande do Sul, v. 26, jan/jul, 2011.

REIGOTA, Marcos. El estado del arte de la educacioón ambiental en Brasil. Tópicos en Educación Ambiental, México, v. 4, n.11, p. 49-62, ago. 2002.

RODRIGUES, C. Educação Infantil e Educação Ambiental: Um Encontro das Abordagens Teóricas com a Pátria Educativa. Revista Eletrônica do Mestrado em Educação Ambiental. Rio Grande do Sul, v. 26, jan/jul , 2011.

TRISTÃO. M. Tecendo os fios da educação ambiental: o subjetivo e o coletivo, o pensado e o vivido. Educação e Pesquisa, v. 31, n. 2, p. 251-264, 2005.

ZAKRZEVSKI, S. B.; SATO, M. Historiando a dimensão ambiental nos programas escolares gaúchos. Pesquisa em Ação Ambiental, v.2, n.2, dez. 2007. 